\title{
EK EN ALKOHOL, ALKOHOL EN EK: FISIOLOGIESE ASPEKTE
}

Wanneer is 'n mens besig om alkohol op 'n verantwoorde wyse te gebruik? Wanneer is 'n mens besig om alkohol te misbruik? Hoe weet 'n mens wanneer vertoon jy die simptome van alkoholisme? Om hierdie vrae te kan beantwoord moet ' $n$ mens jouself ken. In hierdie artikel word met die term alkohol bedoel, etielalkohol in die vorm waarin dit alledaags gebruik word.

Die reaksies wat as gevolg van alkoholisme ontstaan kan in twee hoofgroepe verdeel word naamlik primêre of direkte reaksies en sekondêre of indirekte gevolge. Daar is vier verskynskels wat van belang is naamlik:

1. Direkte fisiologiese en psigologiese effekte. Dit tree op as gevolg van alkohol-inname en is die gevolg van die invloed van alkohol veral op die senuweesisteem.

2. Toleransie of verdraagsaamheid. Dit ontstaan na gereelde inname vir 'n korter of langer tydperk bv weke of maande en beteken dat die liggaam hom aanpas en nou groter hoeveelhede kan verdra voordat dieselfde reaksies ontstaan.

3. Onttrekkings- of onthoudingsverskynsels. Sodra inname van alkohol gestaak word nadat dit vir'n tydlank gereeld gebruik was ontstaan duidelike fisiologiese en psigologiese simptome.

4. Verslawing. Dit is die verskynsel dat die persoon afhanklik geword het van alkohol en hy daaraan verslaaf is of ' $n$ "behoefte" daaraan ontwikkel het.

\section{LIGGAAMSFUNKSIES IN DIE LIGGAAM-GEES-EEN- HEID}

Om te verstaan hoe alkohol die liggaam beïnloed is ' $n$ kort verduideliking van die liggaamsfunksies nodig.

Die mens is 'n liggaam-gees eenheid. Hierdie eenheidsgedagte is baie belangrik. Die liggaam is deel van die eenheid. As een lid ly, ly al die lede van die eenheid. Die mens staan in 'n verhouding tot sy omgewing en reageer altyd as 'n lewende eenheid op sy omgewing. 
Dit kan as volg voorgestel word:

Figuur 1

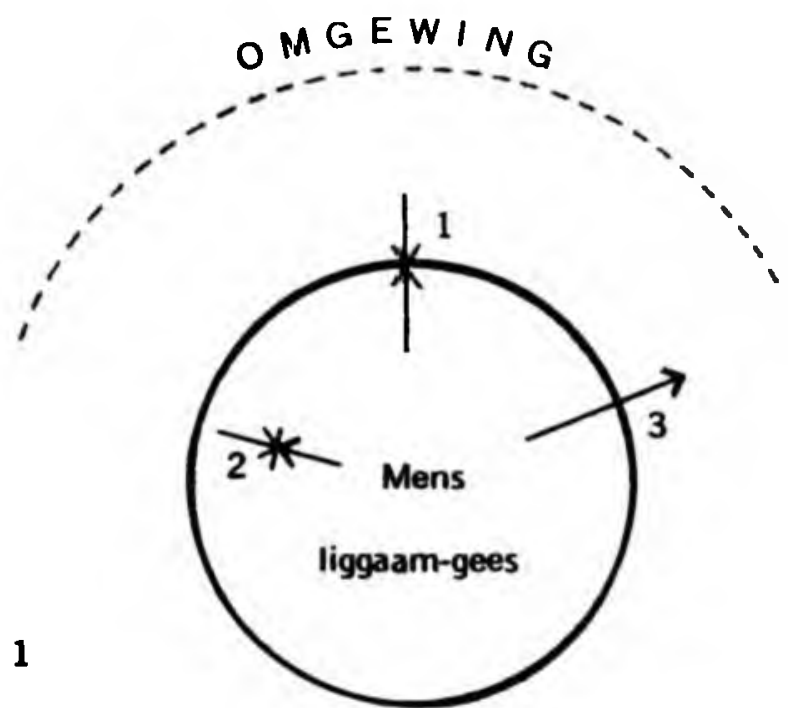

In figuur 1 word die verhouding van die mens tot sy omgewing voorgestel. Die lewende liggaam is ten opsigte van energie en struktuur teenoor die nie-lewende omgewing gestel. Reaksie 1 stel die bedreigings uit die buite-omgewing voor. Teenoor hierdie bedreigings moet die lewende sisteem homself verweer. Hierdie reaksies word bestudeer en beskryf as die algemeenbekende weerstand van 'n lewende sisteem teenoor bedreigings. Die eenvoudigste reaksie van 'n lewende sisteem is blote negatiewe weerstand waardeur sy eie struktuur en funksies en dus voortbestaan verseker word. Hierdie weerstand word deur die negatiewe teruggekoppelde biologiese beheer van die erflike, hormonale, refleksiewe en gedragsbeheersisteme moontlik gemaak.

In Figuur 1 stel reaksie 2 'n tweede bedreiging voor nl inwendige bedreiging wat in die mens self ontstaan. As gevolg van omgewingsinvloede primêr, of sekondêr as gevolg van die mens se reaksie op die omgewingsprikkels en sy eie lewensaktiwiteite, ontstaan inwendige bedreigings wat sy inwendige omgewing kan versteur. Hierdie "besoedeling" van die inwendige omgewing word voortdurend teegewerk deur die inwendige beheersisteme en verwerking of ontgiftiging en uitskeiding van newe- en afvalprodukte. Hierop word ook basies "negatief" gereageer $\mathrm{m}$ a w weerstand gebied $\mathrm{m}$ b v negatiewe 
terugkoppellingsbeheer. Van primêre belang is dat die inwendige omgewing van die liggaam noukeurig beheer word en instand gehou word sodat die eenheid van die liggaam bewaar word en voortbestaan, arbeidsvermoë, produktiwiteit en die vermoë om die omgewing te beheer, behoue bly.

In Figuur 1 stel reaksie 3 die vermoë van die mens om sy omgewing ten goede of ten kwade te verander, voor. Die mens kan met behulp van sy intellektuele vermoëns beheer oor sy binne en buite-omgewing uitoefen.

Die mens as eenheid bestaan op grond van verskillende beheersisteme. Liggaamlik is die mens saamgestel uit miljarde lewende sub-eenhede, die lewende selle wat opgebou is in 'n noukeurige orde-struktuur van weefselsorgane en sisteme. Die beheersisteme maak koördinasie van die funksies van die onderdele moontlik.

Daar is verskillende vlakke van beheer wat volg baie oorvereenvoudig as model voorgestel kan word.

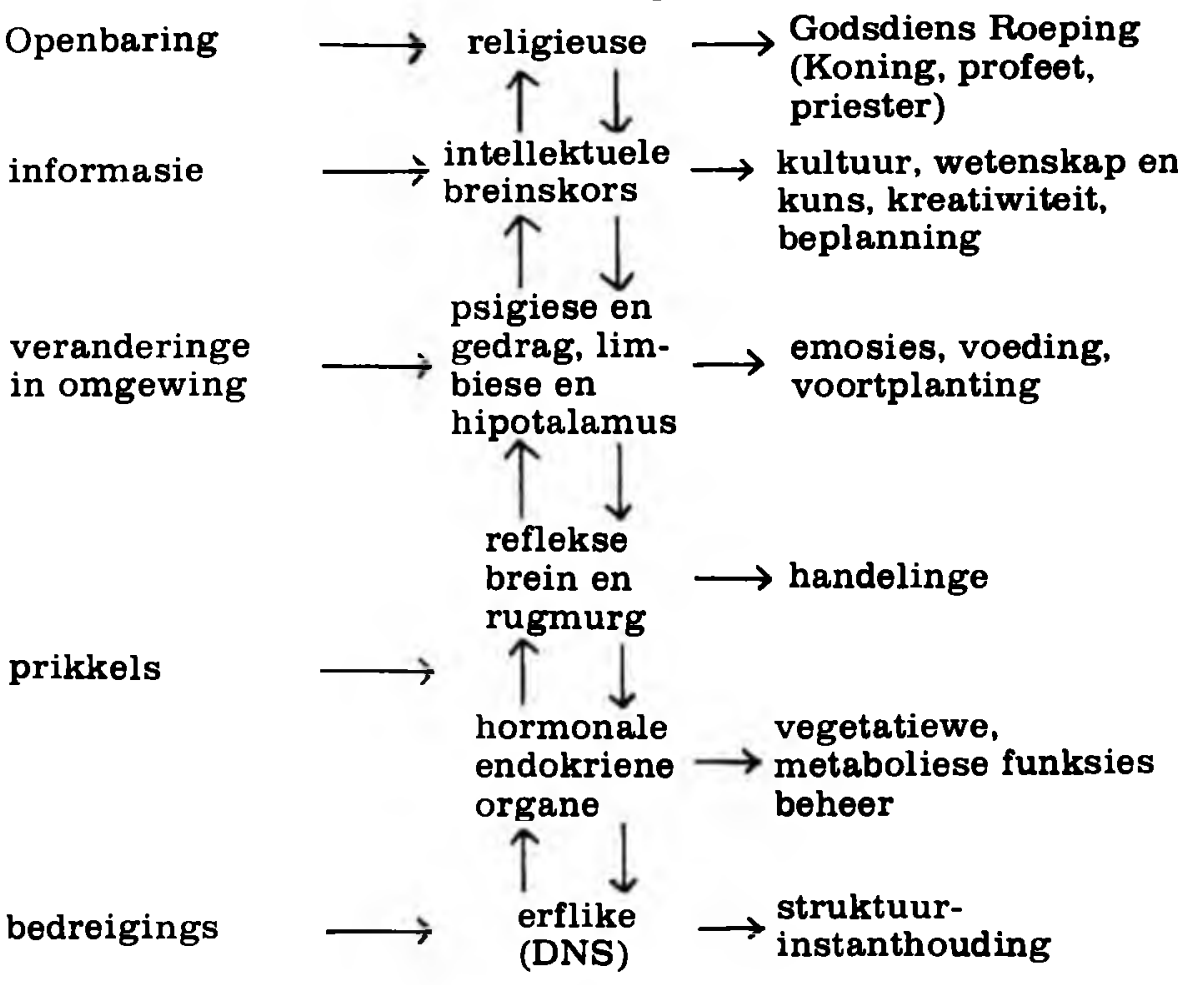




\section{Figuur 2}

Die mees basies biologiese is die erflike beheer waardeur bedreigings van die struktuur afgeweer word en die liggaam dus sy struktuur handhaaf ten spyte van voortdurende bedreigings van verandering en aftakeling. Die tweede vlak is die hormonale beheer waardeur die weefsels en selle so beheer word dat hul funksies aangepas word om die voortbestaan van die hele liggaam te verseker.

Die derde vlak van beheer is die refleksbeheermeganismes. Hierdeur word alle handelinge moontlik gemaak en 'n groot aantal beskermingsmeganismes kom tot stand. Die vierde vlak is die van die psigologiese beheer waardeur veral emosies en gedragspatrone beheer word. Die vyfde vlak is dié van die intellektuele waardeur die mens in staat gestel word om wetenskap en kuns te beoefen en in 'n hoë mate sy volle beheer oor sy buite-en binne-omgewings uit te leef. Die sesde vlak is die religieuse waardeur die mens sy roeping as burger van die Koninkryk van God kan uitleef as koning, profeet en priester. Daar is onderlinge wisselwerkings tussen die vlakke van beheer sodat elk binne sy eie magsgebied funksioneer. So kan hormonale invloede die struktuur binne sekere perke beïnvloed om aanpassings van die funksies te maak bv mitochondria in die selle vergroot of verklein.

Reflekse beïnloed hormonale beheersisteme sodat die hele endokriene beheer onder invloed van die senuweesisteem geintegreer word. So word die verskillende reflekse diensknegte van gedrag waardeur gedragspatrone tot stand kom. Uiteindelik word die hele liggaam ingespan om 'n intellektuele funksie te verrig, bv'n pottebakker maak gebruik van al hierdie vlakke van beheer om sy kunswerk te skep. Hy werk as 'n liggaam-geeseenheid en geeneen van die vlakke van beheer is hierby uitgesluit nie. Uiteindelik is die mens ook as skepsel van God altyd in 'n verhouding tot sy Skepper en sy geloof of ongeloof sal 'n beslissende beheersende rol in sy hele lewe speel. 


\section{DIE INVLOED VAN ALKOHOL OP DIE LIGGAAM}

Wat doen alkohol aan die mens? Alkohol veroorsaak veranderinge in 'n hele aantal beheersisteme van die liggaam. Dit verander die beheersisteme van die liggaam. Dit verander die beheereienskappe, beheervermoë en ontkoppel 'n aantal onderlinge wisselwerkings tussen verskillende beheersisteme. Hierdeur ontstaan meeste van die reaksies wat deur alkohol veroorsaak word. Die beste bewys van versteurde beheer is die vertraagde reflekstyd wat ontstaan.

'n Aantal van die veranderinge en versteurings sal aangetoon word.

Die inname van alkohol in watter vorm ookal, $d w s$ as bier, wyn, brandewyn, whisky of jenewer, veroorsaak dat alkohol deur die maag (20\%) en veral die dunderm $(80 \%)$ in die bloedstroom opgeneem word. Dit is die bloedalkoholwaarde wat bepaal hoe uitgesproke die liggaamreaksies is. In Figuur 3 word 'n hipotetiese bloedalkohol kromme voorgestel. Dit toon hoedat die bloedalkoholkonsentrasie toeneem nadat iemand 'n groot hoeveelheid alkohol vinning ingeneem het. Die styging vind plaas as gevolg van die opname deur die bloed uit die spysverteringskanaal.

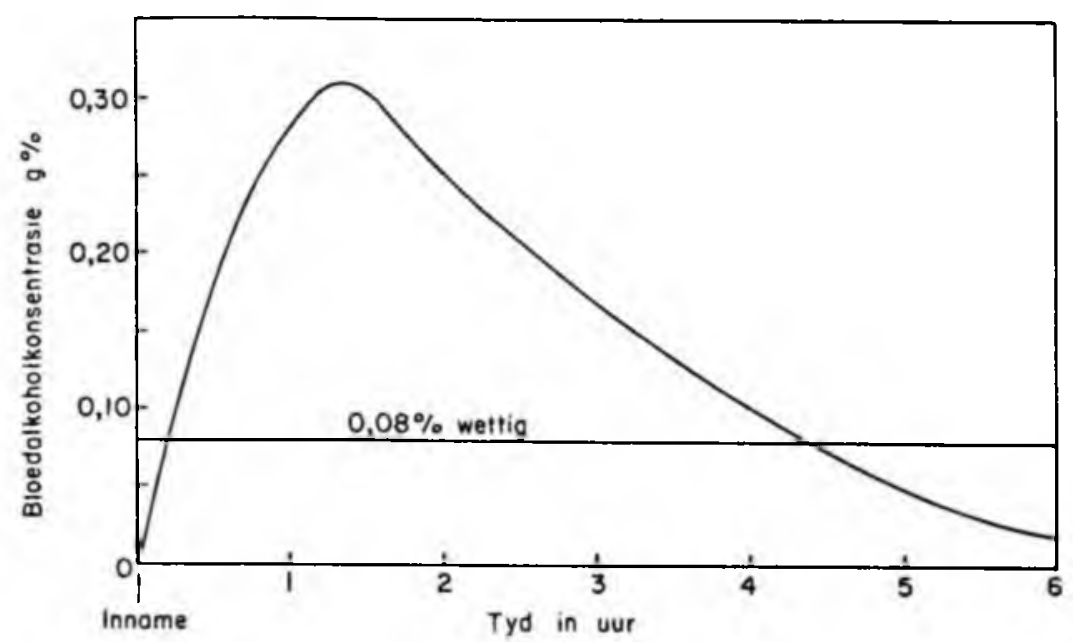

Figuur 3 Bloedalkoholkonsentrasie na inname van $60 \mathrm{~g}$ alkohol 
Hierdie is ' $n$ algemene voorstelling en daar is baie individuele variasie. Verskillende psigiese en fisiologiese veranderinge is waarneembaar by verskillende bloedalkoholwaardes. Daar is groot individuele verskille in reaksie en sensitiwiteit. 'n Oorvereenvoudigde algemene patroon kan as volg voorgestel word:

1. By 0,00 tot $0,05 \mathrm{~g} \%$ (aantal drankies ongeveer 1 tot $1 \frac{1}{2}$ ): Maagsapsekresie verhoog, veral soutsuurafskeiding met min ensieme. 'n Gevoel van euforia (gevoel van welsyn).

2. By 0.05 tot $0.10 \mathrm{~g} \%$ (Wettige grens vir motorbestuur by $0,08 \%$ ). (Aantal drankies ongeveer $1 \frac{1}{2}$ tot $3 \frac{1}{2}$ ):

Begin verskillende verskynsels waarneembaar word. Euforia en maagsuurafskeiding is opvallend en by die nie-tolerante persoon kan tekens van vergiftiging reeds merkbaar word soos opgewondenheid, onstabiele gemoedstemming, pupilverwyding. Reflekse is vertraag.

3. By 0,10 tot $0^{\prime} 15 \mathrm{~g} \%$ ( $3 \frac{1}{2}$ tot 5 drankies) word die gebied van definitiewe vergiftiging bereik. Duidelike simptome soos onstabiele gemoedstemming, vrolikheid en aggressiwiteit wissel af, bewegings raak versteur, ewewigs-, houdings-, stap- en aangeleerde bewegings raak versteur. Oogbewegings en spraak raak beïnvloed.

4. By 0,15 tot $0,20 \mathrm{~g} \%$ is daar ernstige versteuring van oogbewegings, versteurde spraak, versteurde stapbewegings, pupille opvallend verwyd, opgewondenheid, luidrugtigheid en aggresitiwiteit kom voor.

5. By 0,20 tot $0,25 \mathrm{~g} \%$ is ewewig ernstig versteur en stapbewegings moeilik, die persoon struikel en val.

6. By 0,25 tot $0,30 \mathrm{~g} \%$ is die senuweesisteem duidelik verdoof en sal die persoon meestal slaap.

7. By 0,35 tot $0.40 \mathrm{~g} \%$ raak die persoon bewusteloos en tree alkoholnarkose in en kan die asemhaling onderdruk wees.

8. By 0,40 tot $0,60 \mathrm{~g} \%$ raak die persoon in diep narkose of koma en raak die asemhaling opvallend onderdruk 
en kan tot algehele stilstand kom sodat die persoon aan suurstofnood sterf.

Hierdie is ' $n$ baie vereenvoudigde patroon en baie groot individuele variasie kom voor. Veral die "aantal drankies" is baie arbitrêr omdat' $n$ verskeidenheid van faktore dit beinvloed.

Die bloedalkoholkonsentrasie neem af as gevolg van die oksidasie of metabolisme deur die lewer en uitskeiding deur die niere en longe. Alkohol word deur die lewer se ensieme omgesit in asetaldehied en dan in asetaat-eenhede wat dan na koolsuurgas en water afgebreek word of in vette of proteïene omgesit kan word. Alkohol verskaf dus energie maar omdat dit, veral in die vorm van gedistilleerde dranke, geen of weinig vitamiene en minerale bevat, is dit 'n blote kaloriebron sonder enige verdere voedingswaarde en dus van lae biologiese waarde. Ongeveer $90 \%$ van die alkohol word deur die lewer afgebreek en $10 \%$ deur die niere en longe uitgeskei. Die lewer is dus die belangrikste ontgiftigingsorgaan en die liggaam is dus hoofsaaklik van die lewer afhanklik om van die alkohol ontslae te raak. By herhaalde inname van alkohol verbeter die lewer se vermoë om alkohol te ontgiftig mits die lewer ook voorsien word van voldoende ander noodsaaklike voedingstowwe soos vitamiene, minerale en boustowwe soos proteiene, bv swawelbevattende aminosure en vitamiene van die vit. B-kompleks.

Die belangrikste en opvallendste invloed is op die senuweesisteem en $n$ groot aantal van die ander invloede word ook deur senuwee-meganismes beinvloed en beheer. 'n Aantal van die veranderinge word kortliks genoem.

\section{SPYSVERTERINGSISTEEM}

Aanvanklik het alkohol die invloed dat dit maagsapsekresie bevorder maar hoofsaaklik suurafskeiding sterk verhoog. Daarom het dit'n nadelige uitwerking by mense wat reeds aan verhoogde suurafskeiding ly of geneig is daartoe en vanselfsprekend is dit baie nadelig in gevalle waar reeds maagwandbeskadiging bestaan. Dit staan ook in verband met pankreatitis (ontsteking van die pankreas) wat dikwels voorkom by alkoholiste. 


\section{METABOLISME}

Selfs relatief klein hoeveelhede alkohol verhoog vetvorming in die lewer. Met herhaalde gebruik van alkohol verhoog die lewer se vermoë om alkohol af te breek of te verander na vette en proteiene, dit is hierdie meganisme tesame met aanpassings in die senuweesisteem wat waarskynlik vir die verskynsel van verhoogde alkoholtoleransie verantwoordelik is. Metabolisme van die liggaam word ook indirek beïnvloed deur alkohol as gevolg van die invloed op die endokriene sisteem bv verhoogde adrenalienvrystelling.

By die alkoholis word die lewer baie nadelig beïnvloed omdat die oormatige inname van alkohol ook gepaard gaan met wanvoeding. 'n Tekort aan belangrike voedingselemente soos swawelbevattende aminosure afkomstig van proteïene en vitamiene van die vitamien B-kompleks. Dit kom tot stand a $\mathrm{g} v$ verlies van eetlus en versteuring van die eetpatroon en die dieet. Hierdeur ontstaan opvallende lewervervetting en uiteindelik afsterwing van lewerselle en vervanging van die selle met letselweefsel $d$ w s bindweefsel wat onaktief is en nie die funksies van die lewersel kan behartig nie.

Daar is geen grond vir die wanopvatting dat alkohol die metabolisme by spierweefsel verhoog of vermoeienis verdryf of ophef nie. Die gevoel van opheffing van vermoeienis is dus geheel en al 'n sentrale-senuwee-meganisme en nie 'n werklike perifêre metaboliese effek nie. Daarom is die opvatting dat alkohol die liggaam verwarm net so foutief. In werklikheid veroorsaak alkohol dat die liggaam hitte verloor. Dit stimuleer dus nie die verbrandingsprosesse in die liggaam sodat meer energie beskikbaar sou kon kom om die liggaam tot meer in staat te stel nie.

Dit is 'n groot fout om te dink dat alkohol die liggaam verwarm. Dit is net'n illusie wat ontstaan a $g$ v die feit dat die velbloedvate verwyd en die vel rooi en warm word. Daarom is dit baie gevaarlik om aan iemand wat aan skok ly of verkluim, alkohol te gee. Veral vir bergklimmers by hoë hoogtes bo seespieel waar alreeds lae suurstofkonsentrasies heers is alkohol gevaarlik omdat die senuweesimptome wat alkohol veroorsaak baie ooreenstem met dié van suurstoftekort. Die hitteverlies wat deur alkohol 
veroorsaak word is ook ongewens. Daarom word alkohol ook nooit deur poolreisigers gebruik nie.

\section{WATERBALANS}

Alkohol inhibeer die afskeiding van anti-duiretiese hormoon deur die hipofise sodat die herabsorpsie van water in die niere vertraag word en die niere dus meer water uitskei. Die uriene raak verdun en groter volumes water word uitgeskei. Verder word ook meer water deur die vel uitgeskei in die vorm van sweet omdat sweetvorming aangemoedig word. Dit lei dus tot 'n verhoogde verlies van water en 'n negatiewe waterbalans. Dit wek die dorsrefleks op en sal die persoon aanmoedig om vloeistof in te neem.

\section{ASEMHALING}

Klein hoeveelhede alkohol het 'n aanvanklike stimulerende uitwerking op die asemhaling maar later en met groter dosisse word die asemhalingsentrum beheer, onderdruk. Met groot hoeveelhede word die asemhaling tot stilstand kom en die persoon sterf as gevolg van suurstofnood. Dit is een van die redes waarom alkohol nie as narkosemiddel gebruik kan word nie omdat die grens tussen voldoende verdowing om die vel se pynreflekse en sensoriese gewaarwordings deur die breinskors op te hef, en sjirurgie moontlik te maak, en fatale onderdrukking van die asemhalingsentrum baie klein is. Daar is ook verskeie ander omgewensde reaksies soos 'n te lang nawerking en irritasie van die braaksentrum ens.

Alkohol kan in groot hoeveelhede die bloed se suurgehalte $(\mathrm{pH})$ verander as gevolg van vorming van suurmetaboliete bv ketone en aldehiede. Dit het 'n verdere verdowende effek op die senuweesisteem en kan ook die asemhaling verder vertraag waardeur die vrystelling van koolsuurgas verminder en koolsuur in die bloed ophoop wat verdere suurvorming bevorder. So ontstaan 'n kwaadaardige kringloop omdat beheer oor die asemhaling belemmer is.

\section{ENDOKRIENE SISTEEM}

Alkohol het aanvanklik 'n kortdurende stimulerende uitwerking net soos meeste ander algemene narkosemiddels. Gedurende hierdie "opgewonde" fase van narkose- 
toediening word die simpatiese deel van die outonome senuweesisteem gestimuleer en veroorsaak dit $o$ a adrenalienvrystelling deur die byniermedulla en verwyding van die pupille van die oë, versnelling van die pols, ens. Daar is ook aanduidings van verhoogde vrystelling van bynierskorshormone. Hierdie reaksies van die liggaam is tipiese afweer- of weerstandsmeganismes sodat die liggaam in tye van nood verbeterde "veg-of vlugvermoë" bereik. Dit dui daarop dat die liggaam op alkohol aanvanklik reageer as 'n bedreiging.

\section{BLOEDSOMLOOP}

Die invloed op die bloedsomloop is nie baie opvallend nie. Die hartfrekwensie (tempo van die pols) word versnel, die velbloedvate verwyd sodat die vel rooi en warm word. Dit bevorder sweetsekresie en hitteverlies. Die bloeddruk kan effens styg as gevolg van bloedvatvernouing in ander dele van die liggaam en versenelling van die hart. Met hoë dosisse kan ritme-afwykings van die hart ontstaan waarskynlik as gevolg van sekondêre invloede soos elektroliet en $\mathrm{pH}$ versteurings.

Daar is 'n verband tussen alkoholisme en hartsiektes omdat wanvoeding en versteurde metabolisme bevorderlik is vir die ontwikkeling van arterosklerose. Die algemene wanopvatting dat alkohol heilsaam sou wees in sekere gevalle van koronêre hartsiektes berus hoofsaaklik op die waarneming dat die pyn by angina-gevalle dikwels opgehef word deur die inneem van klein tot matige hoeveelhede. Dit sou tot stand kom as gevolg van koronêre bloedvatverwyding. Alhoewel die aanvanklike fase van alkohol-effek 'n matige simpatiese prikkeling veroorsaak en moontlik koronêre bloedvatverwyding kan bewerkstellig is daar vir hierdie opvatting geen eksperimentele of kliniese gronde nie. Wanneer 'n angina pasiënt se elektrokardiogram onder andere, bestudeer word en die effek van alkohol met die van bekende koronêre bloedvatverwyders (bv gliserieltrinitraat) vergelyk word, kan duidelik gesien word dat die tipiese T-golf en ST-segmentveranderinge wat tydens oefening by die pasiënt ontstaan nie deur alkohol opgehef word nie terwyl dit wel in meeste gevalle deur die algemeenaanvaarde middels voorkom word. Die opheffing van die pyn tydens angina is dus waarskynlik net 'n soort sentrale senuwee-verdowingseffek. 


\section{INVLOED OP DIE SENUWEESISTEEM}

Alkohol is nie soos dikwels deur gebruikers verklaar word 'n stimulant nie maar dit is 'n verdowingsmiddel. Dit het' $n$ invloed op die sentrale senuweesisteem en is nie 'n lokale verdowingsmiddel in die hoeveelhede wat dit in die liggaam voorkom tydens inname per mond nie.

Alkohol belemmer die beheervermoë van 'n aantal belangrike senuweesentra. Dit veroorsaak verminderde kontak tussen die sentra sodat 'n ontkoppelingsproses plaasvind waardeur die integrasie en onderlinge wisselwerking en koördinasie belemmer word en verlore gaan. Hierdeur word die integriteit en eenheidswerking van die senuweesisteem belemmer.

Baie min is bekend oor die invloed van klein dosisse by die mens. Wat wel algemeen aanvaar word is dat inhibisiemeganismes opgehef word en dat matige simpatiese prikkeling ontstaan. Dit werk mee tot die gevoel dat die liggaam tot meer in staat is en 'n gevoel van welsyn of euforia. By groter dosisse waar 'n bloedalkoholkonsentrasie styg tot bo $0,10 \%$ is daar duidelike aanduidings van die begin van ontkoppeling van die sentra vir die beheer van gedrag en die hoër of intellektuele sentra.

Twee eienskappe van die senuweesisteem se beheersentra word versteur $\mathrm{nl}$ die basiese vermoë om 'n stabiele dinamiese beheer uit te oefen as beheersisteem en die integrasie met ander beheersentra van 'n hoër orde. Hierdeur word ontkoppeling van die invloed van die hoër sentra bewerkstellig en die beheervermoë verlaag. Daarom tree gedragspatrone eerder as intellektuele funksies na vore en kan by hoër dosisse selfs instinkte oorheers, dit is 'n aanduiding van ontkoppeling en disintegrasie van die eenheid. Die eerste aanduiding van versteurde beheervermoë van die verskillende sentra is die verskynsel van onstabiliteit wat op alle vlakke van die senuweesisteem intree. Aanvanklik is daar onstabiliteit van die gemoedstemming wat kan wissel van vrolikheid en opgewondenheid na neerslagtigheid en aggressiwiteit, op 'n vroeë stadium is daar reeds versteurde beheer van oogbewegings en vertraagde reflekstyd.

Emosies en gedrag word beheer deur die deel van die breinskors bekend as die limbiese sentra. Die hipotalamus speel 'n belangrike rol in hierdie opsig. Dit vorm die 
setel vir verskillende gedragspatrone soos die liggaamsreaksies tydens woede, vrees, voeding, voortplanting ens. Dit beinvloed die hele liggaam deur die beheer wat dit uitoefen op die outonome senuweesisteem en die endokriene sisteem.

Die gedragsentra van die brein staan onder voortdurende modulerende invloed van die hoër sentra. As die wisselwerkings tussen die verskillende sentra egter onderdruk word sal elkeen van die sentra nou as los onderdele begin funksioneer en nie meer as 'n harmoniese eenheid geintegreer in die eenheid van die geheel nie.

Die reflekstyd by meeste refleksbane is vertraag en alle aangeleerde handelinge word versteur - aanvanklik wel baie gering maar namate die dosis styg word dit meer opvallend. Dit sluit dus alle bewegings soos stap, liggaamshouding, en alle noukeurige spierkoördinasie soos by skryf-en spraakbewegings in.

Tipies van 'n onstabiele beheersentrum is dat dit ossillasies begin vertoon $\mathrm{m}$ a $\mathrm{w}$ die funksie wat beheer moet word moet eers 'n afwyking in een rigting vertoon voordat die sentrum "besef" dat dit gevaar inhou en dan word ge-oordorrigeer na die teenoorgestelde kant sodat 'n afwyking in die teenoorgestelde rigting weer sal plaasvind ens. So ontstaan ossillasies van meeste kleiner spierbewegings en ook later versteurings van groter spierbewegings bv die liggaamsposisie, ewewing, stapbewegings ens.

Uit elektro-ensefalografiese studies het duidelik geblyk dat veral die kerngroep van senuweesentra in die middelbrein, breinstam en verlengde rugmurg bekend as die retikulêre aktiveringsisteem (RAS) een van die beheersentra is wat primêr deur alkohol onderdruk word. Hierdie RAS is verantwoordelik vir die beheer van die ewewig tussen slaap en die wakkertoestand. Dit aktiveer die breinskors en is verantwoordelik vir'n groot reeks spiermeganismes.

Belemmering van hierdie fundamentele sentrale beheersisteem veroorsaak belangrike koördinasie en integrasie steurnisse. Om hierdie rede ontstaan by hoër dosisse alkohol die verskynsel van verlies van bewussyn, eers slaap en later alkoholkoma. 
Wat die intellektuele funksies van die brein betref is daar redelike eenstemmigheid dat met selfs matige dosisse die verskillende vermoëns vertraag word. So is bekend dat die leerproses vertraag word en minder effektief plaasvind. Die vorming van assosiasies en gekondisioneerde reflekse is onderdruk en konsentrasievermoë en aandag asook oordeelsvermoë en diskriminasie word verminder. Die totaal hiervan is dat basiese breinfunksie in werklikheid verlaag word en nie verbeter word nie.

\section{VERDRAAGSAAMHEID, SKYNSEL EN VERSLAWING \\ ONTTREKKINGSVER-}

Verdraagsaamheid beteken dat groter hoeveelhede ingeneem moet word voordat dieselfde effek as tevore verkry word. Alkohol word vinniger deur die lewer afgebreek of omgesit in ander onaktiewe stowwe.

Selfs nadat middelmatige hoeveelhede alkohol vir' $n$ tydlank gereeld ingeneem word, ontstaan die verskynsel van onttrekkingsreaksies. Dit begin 'n paar uur (bv 6 tot 7 uur) nadat die laaste dosis alkohol ingeneem is. Die simptome is bewerigheid, naarheid, swakheid, angstigheid en sweetsekresie. Die gedragspatroon van die persoon kan verander sodat hy 'n drang na alkohol vertoon en dit doelbewus soek. In uitgesproke gevalle kan braking voorkom en bewerigheid so erg wees dat die persoon moeilik alledaagse handelinge bv om te skeer, kan uitvoer.

Inname van 'n klein hoeveelheid alkohol hef al hierdie simptome op. Omdat daar geen uitgesproke spysverterings- of enige ander simptome bv gastritis, lewerfunksieversteurings ens hoef te wees nie, kan die simptome nie daaraan toegeskryf word nie. Dit is dus duidelik dat die onttrekkingsimptome as gevolg van die invloed op die senuweesisteem ontstaan.

Tekens van delirium soos hallusinasies kan voorkom en die persoon kan verward raak. Teen die derde dag van baie uitgesproke gevalle kan ernstige delirium voorkom. Koors, uitputting en bloedsomloop-ineenstorting kan in ernstige gevalle voorkom. Indien die persoon nie sterf nie, vind herstel binne ongeveer 'n week plaas.

'n Duidelike bewys van verslawing is die simptome wat tydens onthouding van alkohol-gebruik ontstaan. 
Op die vraag hoe weet ' $n$ mens of jy alkohol misbruik of op die pad na alkoholisme is, is dit dus een van die moontlike toetse m a w ontstaan daar simptome of 'n drang na alkohol na staking van inname van alkohol. Dit is egter nie so eenvoudig nie en sommige outeurs beskryf selfs vyf verskillende tipes alkoholisme. Hiervolgens is daar variërende grade en ook kombinasies van verslawing (fisiologies en psigologies), versteurde voedingsgewoon tes en wanvoeding, sporadiese en episodiese misbruik en verlies van beheer oor alkoholgebruik.

Die grens tussen alkoholgebruik en -misbruik is nie duidelik afgebaken nie. Elke mens behoort oor voldoende kennis van homself, van sy liggaam en gees, te beskik om self te kan besluit waar die grens vir hom is. In terme van die bloedalkoholkonsentrasie sou gestel kan word dat die grens gesoek moet word tussen die waarde wat euforia, 'n gevoel van welsyn, geselligheid en vrolikheid bewerkstellig en die eerste simptome van vergiftiging waar die gemoedstemming onstabiel word, pupilverwyding en die eerste aanduidings van versteuring van spierbewegings intree. Dit is die vlak waar disintegrasie van senuweebeheer begin optree. Dit is moeilik om te veralgemeen omdat daar groot individuele variasie is en die verskynsel van verdraagsaamheid ook 'n rol speel, maar' $n$ algemene riglyn sou wees dat 'n bloedalkoholkonsentrasie van minder as $0,10 \%$ as maksimum vir 'n grens tussen gebruik en misbruik gestel kon word. Vir motorbestuur is $0,08 \%$ wettig.

Die kuns van alkoholgebruik is dus om 'n bloedalkoholwaarde te handhaaf wat binne die grense van die euforiawaarde sonder vergiftigingsimptome is. Hierdeur word dus geselligheid en vrolikheid bereik. Dit beteken dus vir die nie-tolerante persoon om 'n drankie langsaam te gebruik en miskien 'n tweede daarna baie baie langsaam te gebruik sodat oor die hele verloop van 'n gesellige funksie wat 'n middag of ' $n$ aand duur nie meer as een of twee drankies gebruik word nie met die klem op die geselligheid en nie op die alkohol nie. Met gedistilleerde alkoholiese dranke is die grens tussen gebruik en misbruik baie moeilik te bepaal.

Die probleem van verslawing is egter nie so eenvoudig nie omdat selfs klein of matige hoeveelhede alkoholgebruik by herhaling gou 'n gewoonte word en alreeds onttrekkingssimptome by enige mens veroorsaak. As die 
drang na alkohol wat ontstaan egter nie te erg is nie kan die normale gebalanseerde persoon dit self te bowe kom. Maar dit hou vir selfs die sterkstes potensiële gevaar in.

'n Mens se gemoedstemming word deur 'n groot verskeidenheid fisiologiese, psigiese en omgewingsfaktore beinvloed. Dankbare blymoedigheid is die kenmerk van die Christen wat glo dat hy as mens 'n ewigheidsbestemming en roeping het. Alkohol is nie noodsaaklik vir gesellighied nie. 'n Mens kan daarsonder ook goed klaarkom.

\section{P J PRETORIUS PU VIR CHO}

